\title{
Prediction of Container Throughput in China
}

\author{
Zhao Jin1, Yaozong Ding2 \\ ${ }^{1}$ South China University of Technology, Guangzhou, China \\ ${ }^{2}$ Beijing Jiaotong University, Beijing, China \\ Email: 397042520@qq.com
}

How to cite this paper: Jin, Z., \& Ding, Y. Z. (2018). Prediction of Container Throughput in China. Chinese Studies, 7, 12-20. https://doi.org/10.4236/chnstd.2018.71002

Received: November 23, 2017

Accepted: January 28, 2018

Published: February 1, 2018

Copyright (c) 2018 by authors and Scientific Research Publishing Inc. This work is licensed under the Creative Commons Attribution International License (CC BY 4.0).

http://creativecommons.org/licenses/by/4.0/

\begin{abstract}
In this paper, we will use the time series analysis method to predict the throughput of the research, through the establishment of time series SARIMA model, using the January-February 2017 domestic container throughput statistics of the main container port forecast from March 2017 to December 2020 container throughput data and analyze the trend of the throughput of major container ports in China in the coming year according to the forecast results. At the same time, we will use $\mathrm{R}$ software to analyze the time series of the throughput of China's major container ports. By decomposing the time series and correcting the seasonal differences of the data, a seasonally revised time series chart is obtained. Based on the above analysis, this paper predicts that by 2020 China's major container port throughput will be at the level of 250 million TEU-270 million TEU.
\end{abstract}

\section{Keywords}

Container Port, Throughput, Time Series Analysis, SARIMA Model

\section{Introduction}

In the context of world economic integration, international trade is increasingly frequent. As the most widely used means of transport in international trade, container shipping not only promotes the mechanization and automation of transportation production, but also greatly improves the efficiency of international transportation and reduces the transportation cost. Chinese foreign trade activities are very frequent. But in recent years, the changes in the international and domestic transportation environment have caused the balance of supply and demand of container transport to change. On the one hand, with the economic restructuring in our country, the labor-intensive industries are gradually shrinking. The transition of foreign trade products to "technology-based" com- 
modities has led to changes in the demand for container transport. On the other hand, since the 21st century, the construction of large-scale ports in our country has greatly increased the handling capacity of container ports in our country. The supply of container transport has also undergone great changes. Forecasting the throughput of container ports has increasingly become a topic of concern to the industry.

The research of this paper is based on the actual situation of the port, combines the achievements of the relevant scholars in this field and makes innovations and improvements, and uses the time series analysis method to analyze the data of container port transportation dynamically. And we combine the latest transport market situation to analyze the container port transport, which has some guidance on the production of first-line transport.

\section{Literature Review}

In the actual statistics, the throughput of the container port is a time series of random fluctuations influenced by various factors such as economy and politics. Therefore, the forecast of container port throughput has some difficulties and uncertainties in the research. Many scholars put forward many prediction models and methods in the prediction of container port throughput. The most common prediction methods are curve fitting method, regression analysis method, gray prediction method, nonlinear trend analysis method and neural network method. Jian Ye (2005) introduced four classic series models: time series model, gray series model, regression model and artificial neural network model. On the basis of cluster analysis, the main coastal ports of China are divided into three different growth ports according to the growth characteristics of their respective container traffic volume. The growth of these three types of ports were ordinary growth, accelerated growth and volatility growth, different growth ports in the prediction of container throughput forecast model used is also different. The study predicts the throughput of China's major coastal container ports and summarizes the forecasting methods that should be used for container ports of different growth types. Xing Xu and Xijun Shi (2002) introduced the BP learning and generalization advantages of BP artificial neural network model in forecasting container port throughput in Shenzhen Port. Xidong Zhai (2006) relied on the transportation background of Dalian Port and predicted the container throughput of Dalian Port by GM $(1,1)$ residual correction prediction model and completing the validation of the model. Xinhua Ma (2010) based on the original data of the container throughput of China's major ports in his research, conducted a prediction study using the spatial state model. In Xiaomeng Zhu's study (2014), the relatively novel time series formed by the complementary advantages of time series analysis and causal analysis. In this model, GDP replaces the time factor in the traditional time series forecasting method as a new explanatory variable. Based on the container throughput data of Wuhan Port in recent ten years, Yamei Peng (2016) used gray forecasting model and regression analysis model to construct a combined model to forecast the container through- 
put of Wuhan Port in the coming period.

In this paper, the seasonal variation of the time series of container port throughputs is obtained by using the Autoregressive Moving Average Model (SARIMA) and the model established in $\mathrm{R}$ software. And we forecast the throughput of China's major container ports in the next 4 years in the future. Based on the analysis of the impact of China's economic development and the throughput of foreign trade on the throughput of container ports, we corrected the results predicted by the model.

\section{Model}

1) Model description

ARIMA, the differential autoregressive moving average model, consists of three parts. One is autoregression (AR part). The current value of a time series can be expressed as a linear combination of lagged P-period observations; The second is the whole (I (d) part), $d$ is the number of difference required for the time series to become a stationary sequence; Third, the moving average (MA part), that the current value of the time series can be expressed as a linear combination of q-order residuals. The expression of the model is:

$$
W_{t}=C+\varphi_{1} X_{t-1}+\cdots+\varphi_{p} X_{t-p}+\epsilon_{t}-\theta_{1} \epsilon_{t-1}-\cdots-\theta_{q} \epsilon_{t-q}
$$

$W_{t}$ : variables after the d-order difference; $\varepsilon$. moving average;

$p$ : autoregressive terms; q: moving average term.

2) Data sources and analysis

The data in this paper come from the data of China Transportation Database. Since China joined the WTO in 2001, we take the monthly data of the container throughput of the major ports in the country from January 2001 to February 2017 as the research object. The data are shown in Table 1.

The throughput data of container ports in China are analyzed, and the form of test is judged from the time series chart, the results shown in Figure 1. It can be seen from the figure that the throughput fluctuates relatively large. Generally, from 2001 to 2017, it has been an upward trend and has some cyclical changes. In February, throughput has reached the lowest throughout the year. In December monthly throughput reached its maximum. Therefore, the time series of throughput consists of three parts: the trend part, the seasonal part and the irregular part.

In this paper, the time series is decomposed into three parts according to the results shown in Figure 2. Figure 2 is divided into four parts, from top to bottom: the original time series and the estimated trend, the season Graphs and irregular graphs.

As can be seen from Figure 2, the estimated trend has steadily risen year by year since 2001 and declines around 2009, but then steadily increased. Figure 2 estimated the seasonal part of the image is stable, indicating that the container port throughput there is a certain seasonal pattern, consistent with the previous analysis. 
Table 1. Monthly domestic container port throughput.

\begin{tabular}{|c|c|c|c|c|c|c|c|c|c|c|c|}
\hline Jan & Feb & Mar & Apr & May & Jun & Jul & Aug & Sep & Oct & Nov & Dec \\
\hline 2001188.00 & 170.60 & 212.80 & 212.00 & 205.40 & 217.30 & 221.70 & 237.30 & 248.40 & 246.20 & 235.70 & 341.35 \\
\hline 2002247.60 & 206.10 & 264.40 & 282.70 & 285.60 & 298.80 & 304.10 & 328.00 & 337.50 & 319.30 & 335.70 & 429.60 \\
\hline 2003342.22 & 273.50 & 368.30 & 372.41 & 376.31 & 387.24 & 393.87 & 433.13 & 427.12 & 438.42 & 439.30 & 558.23 \\
\hline 2004421.93 & 384.98 & 458.75 & 481.79 & 486.86 & 504.25 & 506.00 & 532.91 & 549.77 & 550.45 & 542.98 & 690.97 \\
\hline 2005573.31 & 444.05 & 560.81 & 607.17 & 611.67 & 608.76 & 637.03 & 661.55 & 665.95 & 662.54 & 660.73 & 796.22 \\
\hline 2006688.57 & 539.89 & 704.18 & 736.49 & 740.39 & 754.26 & 782.30 & 800.83 & 833.25 & 827.14 & 820.87 & 1006.68 \\
\hline 2007849.29 & 763.35 & 803.57 & 914.21 & 912.00 & 949.21 & 943.87 & 980.31 & 1008.06 & 985.90 & 989.29 & 1203.08 \\
\hline \multicolumn{12}{|l|}{20081044.06} \\
\hline 2009899.13 & 706.02 & 942.24 & 935.87 & 1020.49 & 1003.30 & 1056.41 & 1088.87 & 1107.10 & 1078.11 & 1085.23 & 31129.78 \\
\hline \multicolumn{12}{|l|}{20101135.53} \\
\hline \multicolumn{12}{|l|}{20111350.47} \\
\hline \multicolumn{12}{|c|}{20121363.431193 .461408 .471439 .431512 .281499 .851510 .471511 .641587 .651508 .221527 .951598 .28} \\
\hline \multicolumn{12}{|c|}{20131549.991217 .961529 .031573 .711613 .471604 .091649 .501638 .521626 .121594 .871638 .641674 .24} \\
\hline \multicolumn{12}{|c|}{20141656.491277 .111632 .111675 .381681 .501696 .191704 .641756 .381725 .951737 .741755 .811777 .93} \\
\hline \multicolumn{12}{|c|}{20151784.051432 .451674 .141762 .471793 .491780 .361792 .721789 .881776 .541744 .461788 .841789 .68} \\
\hline \multicolumn{12}{|c|}{20161808.231427 .281760 .201816 .551838 .341846 .391881 .091911 .931857 .411847 .101879 .581834 .95} \\
\hline 20171858.9 & 1537.96 & & & & & & & & & & \\
\hline
\end{tabular}

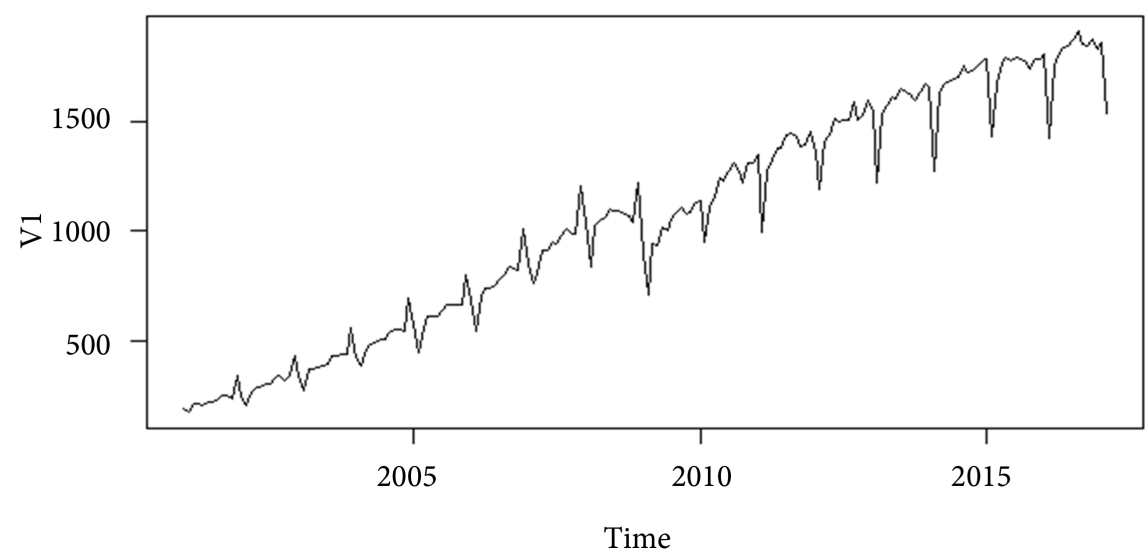

Figure 1. Sequentially.

\section{3) Stationarity test}

Unit root test of container throughput data, due to the upward trend in the time series, the unit root test needs to include both intercept and trend items. As shown in Figure 3, the ADF test of the throughput time series shows that the $\mathrm{P}$ value ratio is much larger than the default $\mathrm{p}$ value (0.05), and we can see that the null hypothesis can not be rejected. The sequence is not stable. Therefore, a difference of the throughput sequence is made to obtain a Dttl sequence and an ADF test on the Dttl sequence. As shown in Figure 4, a P value of 0.01 is smaller 
Decomposition of additive time series

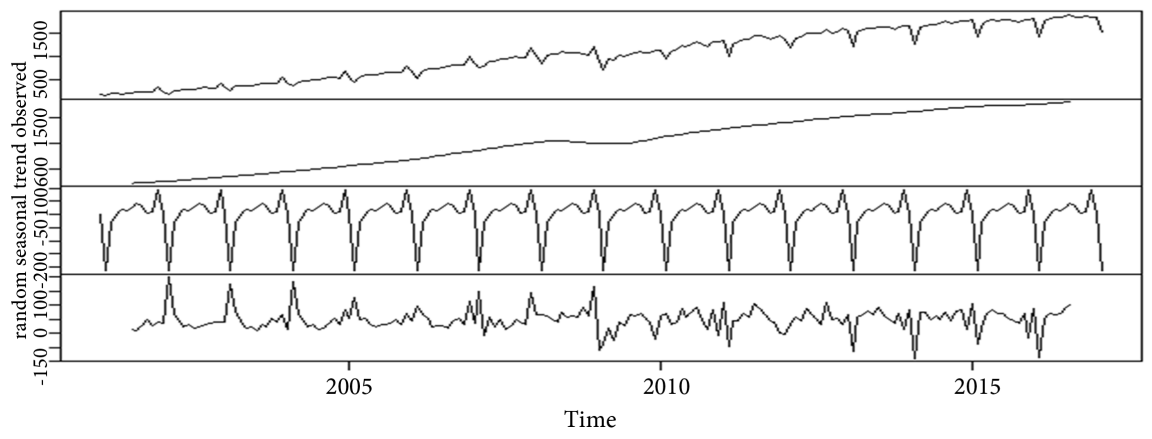

Figure 2. Time series decomposition.

\begin{tabular}{l} 
Augmented Dickey-Fuller Test \\
Test Results: \\
PARAMETER: \\
Lag Order:11 \\
STATISTIC: \\
Dickey-Fuller: 7.855 \\
P VALUE: 0.99 \\
p-value greater than printed p-value \\
\hline
\end{tabular}

Figure 3. ADT test of throughput ttl time series.

Augmented Dickey-Fuller Test
Test Results:
PARAMETER:
Lag Order:11
STATISTIC:
Dickey-Fuller: -9.2901
P VALUE: 0.01
p-value smaller than printed p-value

Figure 4. D (throughput) ADF test.

than a default $\mathrm{P}$ value (0.05), so that the original hypothesis can be rejected and the Dttl sequence obtained is stable.

4) Model estimation and parameter setting

Through the correlation analysis of Dttl (throughput), it is found that in the multiple of 12, as shown in Figure 5, Figure 6, the autocorrelation coefficient is not significant, so the sequence is seasonal and seasonal difference is needed. Therefore, this article selects seasonal ARIMA model or SARIMA model.

After making a seasonal difference adjustment on Dttl, we denote the autocorrelation diagrams and the autocorrelation diagrams of the sequences 
V1

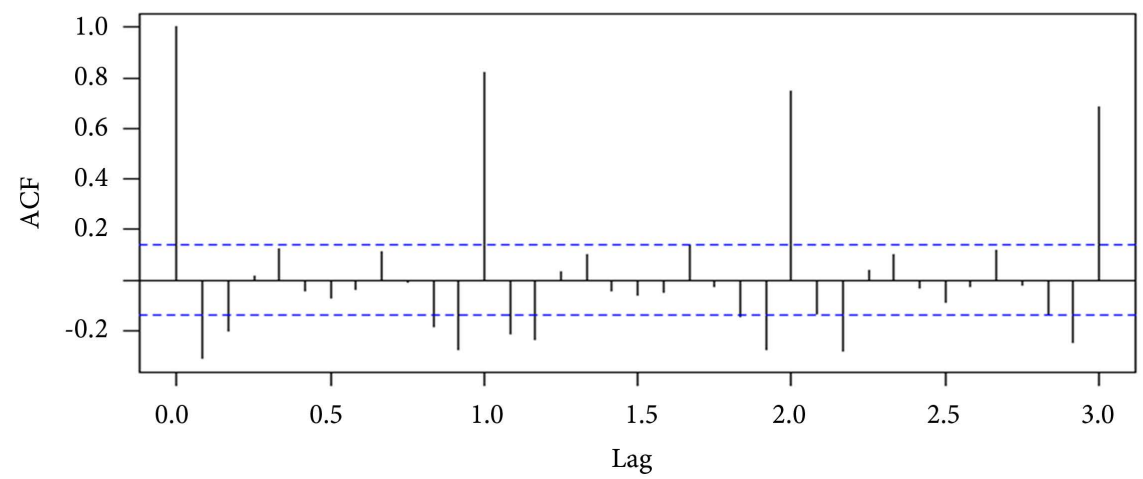

Figure 5. Dttl's autocorrelation function.

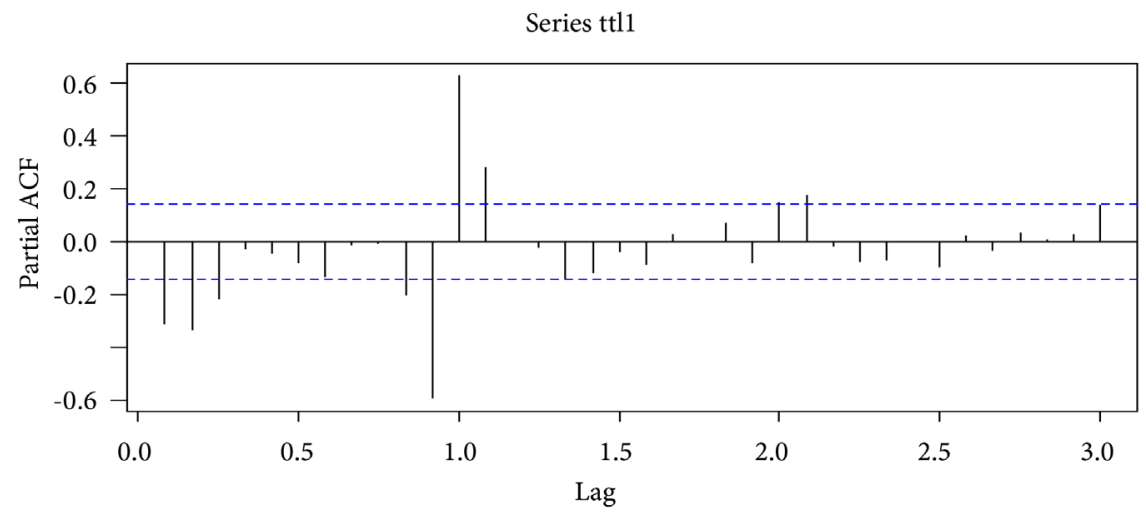

Figure 6. Partial autocorrelation function of Dttl.

SDttl and SDttl, as shown in Figure 7, Figure 8, we can see that the seasonal autocorrelation gradually disappears after the first order.

According to the autocorrelation and partial autocorrelation of sequences, we found that SARIMA, $(2,1,2)(2,1,1) 12$, AIC is the smallest, which is selected according to the AIC principle. Model parameters are shown in Figure 9.

5) Residual analysis

Figure 10 shows the residual analysis. It can be seen that the residuals have no autocorrelation and according to Ljung-Box, all $\mathrm{P}$ values are greater than 0.5. Therefore, the model is established.

6) Analysis of forecast results

Using the obtained SARIMA model to predict the throughput of container ports nationwide and get the forecast conclusion. As shown in Table 2, it can be seen from the results that throughput will continue to increase in the future, decreasing in February of each year and increasing in December.

\section{Conclusion}

Although China's GDP growth will stabilize at 6.5\% during the "13th Five-Year Plan" period, economic and industrial institutions will face a transformation and the throughput growth of major ports will slow down further. However, the 
V1

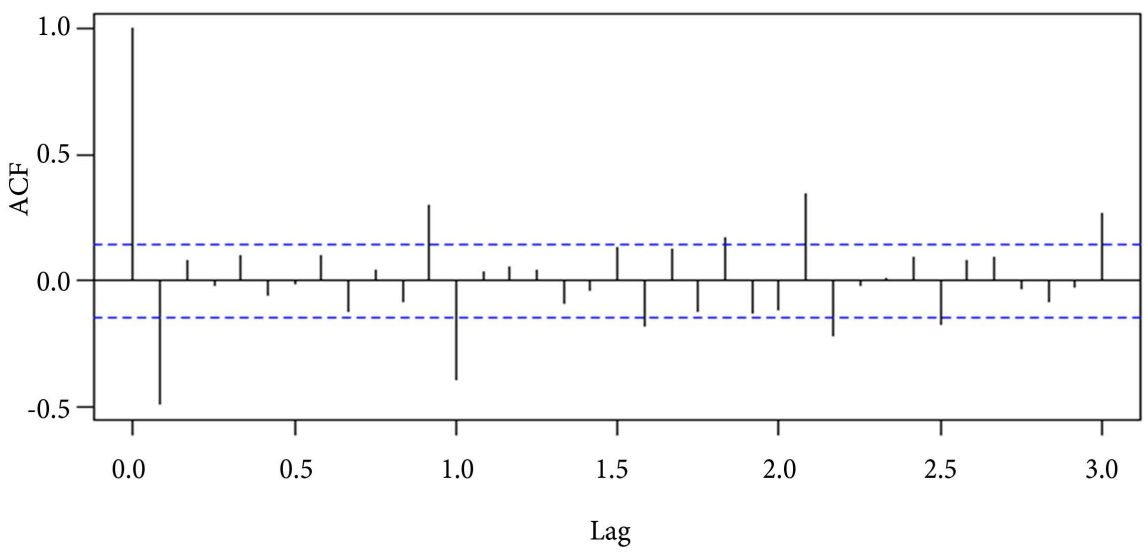

Figure 7. SADttl's autocorrelation function.

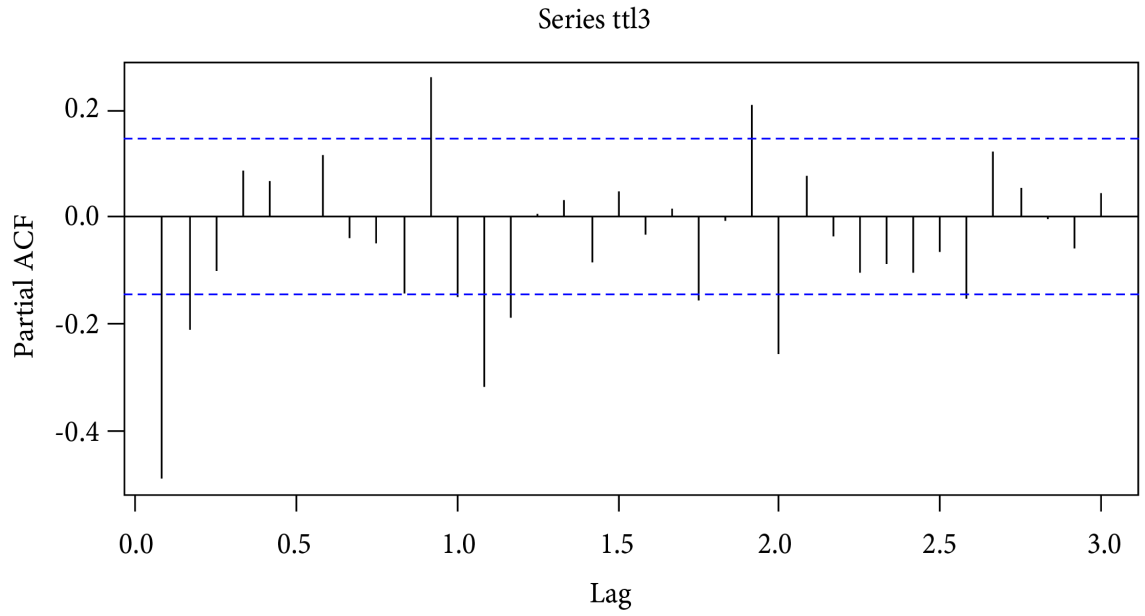

Figure 8. Partial autocorrelation function of SADttl.

$\operatorname{ARIMA}(x=t \mathrm{tl}$, order $=c(2,1,2)$, seasonal $=$ list $($ order $=c(2,1,1)$, period $=12))$

Coefficients:

\begin{tabular}{lccccccc} 
& ar1 & ar2 & ma1 & ma2 & sar1 & sar2 & sma1 \\
& -0.3095 & -0.1349 & -0.3113 & 0.1020 & -0.9293 & -0.4045 & 0.4148 \\
s.e. & 0.9178 & 0.2933 & 0.9221 & 0.3215 & 0.2720 & 0.1124 & 0.3015 \\
sigma^2 & estimated & as 1570: & log likelihood $=$ & -925.2, & aic $=1866.4$ \\
\hline
\end{tabular}

Figure 9. Model parameters.

restructuring of China's port structure is tending to be rationalized and the proportion of container shipping will further increase. With the further release of the favorable strategy of "One Belt, One Road" and other major strategies, the throughput of China's major container ports will also maintain a relatively steady growth. Based on the above analysis, this paper predicts that by 2020 China's major container port throughput will be at the level of 250 million 
Standardized Residuals

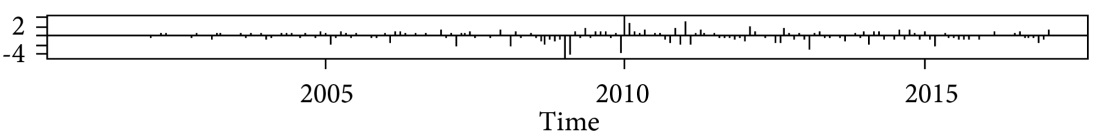

ACF of Residuals

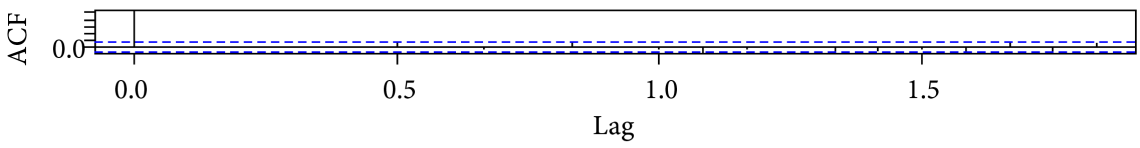

$p$ values for Ljung-Box statistic

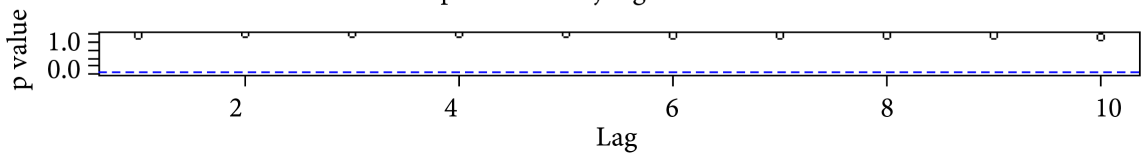

Figure 10. SADttl Residual Analysis.

Table 2. Predicted results.

\begin{tabular}{|c|c|c|c|c|c|}
\hline Point & Forecast & Lo 80 & Hi 80 & Lo 95 & Hi 95 \\
\hline Mar-17 & 1805.988 & 1754.660 & 1857.317 & 1727.488 & 1884.489 \\
\hline Apr-17 & 1876.891 & 1822.622 & 1931.161 & 1793.893 & 1959.890 \\
\hline May-17 & 1903.077 & 1842.421 & 1963.733 & 1810.312 & 1995.842 \\
\hline Jun-17 & 1903.645 & 1836.591 & 1970.700 & 1801.095 & 2006.196 \\
\hline Jul-17 & 1927.827 & 1854.810 & 2000.844 & 1816.157 & 2039.497 \\
\hline Aug-17 & 1947.261 & 1868.709 & 2025.813 & 1827.126 & 2067.369 \\
\hline Sep-17 & 1914.621 & 1830.894 & 1998.347 & 1786.572 & 2042.669 \\
\hline Oct-17 & 1897.140 & 1808.540 & 1985.740 & 1761.638 & 2032.642 \\
\hline Nov-17 & 1932.018 & 1838.799 & 2025.238 & 1789.452 & 2074.585 \\
\hline Dec-17 & 1918.465 & 1820.844 & 2016.085 & 1769.167 & 2067.762 \\
\hline Jan-18 & 1933.937 & 1832.106 & 2035.769 & 1778.200 & 2089.675 \\
\hline Feb-18 & 1586.992 & 1481.117 & 1692.866 & 1425.070 & 1748.913 \\
\hline Mar-18 & 1878.028 & 1759.900 & 1996.156 & 1697.367 & 2058.689 \\
\hline Apr-18 & 1944.030 & 1820.238 & 2067.822 & 1754.706 & 2133.354 \\
\hline May-18 & 1969.121 & 1938.610 & 2099.632 & 1769.521 & 2168.720 \\
\hline Jun-18 & 1970.818 & 1933.710 & 2107.926 & 1761.129 & 2180.507 \\
\hline Jul-18 & 1996.685 & 1853.241 & 2140.129 & 1777.306 & 2216.064 \\
\hline Aug-18 & 2017.961 & 1868.441 & 2167.481 & 1789.290 & 2246.633 \\
\hline Sep-18 & 1981.780 & 1826.420 & 2137.140 & 1744.177 & 2219.383 \\
\hline Oct- 18 & 1965.460 & 1804.471 & 2126.448 & 1719.248 & 2211.671 \\
\hline Nov-18 & 1999.950 & 1833.522 & 2166.377 & 1745.421 & 2254.479 \\
\hline Dec-18 & 1981.368 & 1809.675 & 2153.062 & 1718.785 & 2243.951 \\
\hline Jan-19 & 1998.227 & 1821.424 & 2175.030 & 1727.830 & 2268.624 \\
\hline
\end{tabular}




\section{Continued}

\begin{tabular}{|c|c|c|c|c|c|}
\hline Feb-19 & 1655.474 & 1473.705 & 1837.243 & 1377.482 & 1933.466 \\
\hline Mar-19 & 1942.788 & 1747.961 & 2137.615 & 1644.826 & 2240.750 \\
\hline Apr-19 & 2009.583 & 1807.991 & 2211.175 & 1701.275 & 2317.891 \\
\hline May-19 & 2034.851 & 1825.373 & 2244.329 & 1714.482 & 2355.220 \\
\hline Jun-19 & 2036.366 & 1819.073 & 2253.659 & 1704.045 & 2368.687 \\
\hline Jul-19 & 2061.960 & 1837.079 & 2286.840 & 1718.035 & 2405.885 \\
\hline Aug-19 & 2082.938 & 1850.710 & 2315.167 & 1727.775 & 2438.101 \\
\hline Sep-19 & 2047.330 & 1807.977 & 2286.683 & 1681.271 & 2413.389 \\
\hline Oct-19 & 2030.822 & 1784.550 & 2277.093 & 1654.181 & 2407.462 \\
\hline Nov-19 & 2065.375 & 1812.373 & 2318.376 & 1678.442 & 2452.307 \\
\hline Dec-19 & 2047.606 & 1788.050 & 2307.163 & 1650.648 & 2444.564 \\
\hline Jan-20 & 2064.241 & 1798.290 & 2330.192 & 1657.505 & 2470.978 \\
\hline Feb-20 & 1720.810 & 1448.616 & 1933.004 & 1304.525 & 2137.095 \\
\hline Mar-20 & 2008.726 & 1723.521 & 2293.931 & 1572.542 & 2444.910 \\
\hline Apr-20 & 2075.393 & 1782.354 & 2368.432 & 1627.228 & 2523.557 \\
\hline May-20 & 2100.632 & 1798.801 & 2402.463 & 1639.021 & 2562.242 \\
\hline Jun-20 & 2102.176 & 1791.617 & 2412.736 & 1627.217 & 2577.136 \\
\hline Jul-20 & 2127.814 & 1808.727 & 2446.902 & 1639.812 & 2615.816 \\
\hline Point & Point & Point & Point & Point & Point \\
\hline Aug-20 & 2148.841 & 1821.440 & 2476.242 & 1648.124 & 2649.557 \\
\hline Sep-20 & 2113.140 & 1777.630 & 2448.650 & 1600.022 & 2626.258 \\
\hline Oct-20 & 2096.662 & 1753.234 & 2440.090 & 1571.434 & 2621.890 \\
\hline Nov-20 & 2131.205 & 1780.037 & 2482.373 & 1594.141 & 2668.269 \\
\hline Dec-20 & 2113.305 & 1754.565 & 2472.045 & 1564.659 & 2661.951 \\
\hline
\end{tabular}

TEU-270 million TEU.

\section{References}

Jian, Y. (2005). Study on Port Container Throughput Prediction Based on Cluster Analysis. Dalian University of Technology.

Ma, X. H. (2010). Research on the Balance between Supply and Demand of Container Port Throughput in China. Dalian Maritime University.

Xu, X., \& Shi, X. J. (2002). Real-Time Forecasting Model of Shenzhen Port Based on BP Neural Network. Journal of Hohai University (Natural Science).

Zhai, X. D. (2006). Study on Container Container Throughput Prediction Model. Dalian University of Technology.

Zhu, X. M. (2014). Study on the Correlation Model of Container Throughput and GDP in Coastal Ports. Dalian Maritime University. 